\title{
Net profit or net loss?
}

J.H.S. Blaxter

Scaling Fisheries: The Science of Measuring the Effects of Fishing, 1855-1955. By Tim D. Smith. Cambridge University Press: 1994. Pp. 392. £50, \$74.95.

Net Loss: Fish, Jobs and the Marine Environment. By Peter Weber. Worldwatch Institute: 1994. Pp. 76. \$5 (pbk).

On the Sex of Fish and the Gender of Scientists: A Collection of Essays on Fisheries Science. By Daniel Pauly. Chapman and Hall: 1994. Pp. 250. £35.

THE most recently available statistics from the United Nation's Food and Agriculture Organization give a worldwide fish catch of 97 million tonnes in 1991 , of which 82 million tonnes were taken in the sea. In fact, the world fish catch grew at an annual rate of nearly 6 per cent after the Second World War but is now increasing at only about 2 per cent. These facts may seem

\section{IMAGE UNAVAILABLE FOR COPYRIGHT REASONS}

\section{Caught in the act - herring fishing.}

surprising given the constant and very public concern of politicians, managers and scientists about the poor health of fish stocks, with nearly all of the fish caught through hunting rather than raised in capitivity.

A closer analysis shows a fluid and impermanent structure to the aggregate catch; over the years, some stocks have disappeared, others have been overexploited and allowed to recover, still others have recovered of their own accord. Most importantly, new species have been exploited. In the 1960 s and early 1970 s a clupeoid (the anchoveta) dominated the catch in terms of weight, if not value. Today the most important species is a gadoid, the Alaska pollack, which has contributed 5-6 million tonnes annually over the past decade.

The alarms and concerns of scientists from the earliest days of fishery science are well described in Scaling Fisheries. In the second half of the nineteenth century, high-seas fishing became increasingly important (and apparently even threatening to the stocks) as the use of steam to drive vessels and winches bolstered the power of the fleet. That high-seas fish stocks were a resource shared among nations was abundantly clear, with international collaboration thriving from the

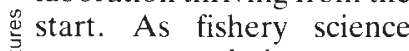
đ grew, new techniques were quickly developed. Two of the most important were the determination of the age structure of stocks and to therefore the ability to determine growth, and tagging of fish to investigate migrations. Later, the invention of the echo-sounder made it possible to follow concentrations of fish from day to day and, much later (beyond the historical scope of the book), to determine their biomass.

A sophisticated younger reader of the book may be amazed at the apparent naivety of the first fishery biologists. They seemed to have had some pretty cockeyed ideas, which could have been easily dispelled by modern equipment, techniques and insights. But bear in mind, to give an example, that in the late 1800 s fish eggs could not be identified to species, so the technique of biomass estimation from a census of early life-history stages was not an option.

Methods of management have swung in and out of favour. One of the most notorious was the idea of planting large numbers of eggs or newly hatched fish larvae in the sea to enhance stocks. Some countries maintained this expensive practice long after it was shown to be useless. Yet today the idea has been resuscitated, but this time with the planting out of much older stages, which are better able to fend for themselves.

One of the most severe problems for both fishery scientists and managers is the large year-to-year variation in recruitment to fish stocks. Remedial measures are taken against a very 'noisy' background, often making it difficult to determine whether a measure has been successful or not. To obtain a maximum sustainable yield from a stock - obviously the best long-term goal - it was realized early on that young fish must be allowed to enter the stock and not be caught by the nets. Much early management depended on increasing the mesh size of the nets to allow the small young fish to pass through and on establishing minimum sizes for landing; these practices are still of great importance. More recently, again outside the scope of the book, total allowable catches have been introduced so that the catch of a particular stock may be divided among the appropriate fishery nations. Even this package of measures is failing to allow over-exploited stocks to recover and it has been realized for some time that fishing pressure must be reduced by restricted entry or reduction of the number of fishing vessels. The most dramatic demonstrations of the effects of reduced fishing were the high takes of fish in European waters after the First and Second World Wars.

Tim Smith's book makes interesting reading for scientists and historians. Readers without specialized knowledge will understand it if they read it from the beginning. The style would have been more coherent if there had been fewer digressions and minutiae about the early fishery scientists themselves. Perhaps these were included to leaven the rather heavy main material, but they succeed only in deflecting readers. Another irritation is the constant jumping from one decade to another and back again, making it difficult to follow a theme. More regrettably, the author cuts off the historical account in 1955 , preventing one from relating the herculean efforts of the earlier fishery scientists to more recent developments.

In Net Loss, Peter Weber takes up the tale 40 years later with a useful booklet on the present dangers to our fisheries and fishermen, not only from overexploitation but also from pollution; he emphasizes the over-capacity of the fleets. Daniel Pauly's curiously misnamed book is a collection of essays on fishing with an emphasis on the tropics and developing countries. As might be expected, the problems of recruitment and overexploitation are prominent. Its aim of getting away from the "relentless parochialism of the average published paper" succeeds, but it should never be forgotten that these papers are the breadand-butter of the fishery scientist. So speaks the editor of a journal of marine science!

J. H. S. Blaxter is at the Scottish Association for Marine Science, PO Box 3, Oban, Argyll PA34 4AD, UK. 